\title{
KINETICS AND MECHANISM OF OXIDATION OF MALIC ACID BY N-BROMONICOTINAMIDE (NBN) IN THE PRESENCE OF A MICELLAR SYSTEM
}

\author{
L. Pushpalatha \\ Postgraduate and Research Department of Chemistry, National College, Trichy — 620001 , \\ Tamil Nadu, India.
}

E-mail address: lathaa_ramesh@yahoo.com

Keywords: Malic acid; N-Bromonicotinamide; oxidation; micellar effcet

\begin{abstract}
The oxidation of malic acid by N-bromonicotinamide in the presence of micellar system is studied. First order kinetics with respect to NBN is observed. The kinetics results indicate that the first order kinetics in hydroxy acid at lower concentrations tends towards a zero order at its higher concentrations. Inverse fractional order in $\left[\mathrm{H}^{+}\right]$and [nicotinamide] are noted throughout its tenfold variation. Variation of $\left[\mathrm{Hg}(\mathrm{OAc})_{2}\right]$ and ionic strength of the medium do not bring about any significant change in the rate of reaction. Rate of the reaction increases with a decrease in the percentage of acetic acid. Decrease in the rate constant was observed with the increase in [SDS]. The values of rate constants observed at four different temperatures were utilized to calculate the activation parameters. A suitable mechanism consistent with the experimental findings has been proposed.
\end{abstract}
Abbreviations
NBN N-Bromonicotinamide
MA Malic acid
NA Nicotinamide
SDS Sodium dodecyl sulphate

\section{INTRODUCTION}

The kinetics of the oxidation of hydroxy acids has been studied with a number of oxidizing agents like potassium bromate, hexamethylenetetraminebromine, sodium Nchlorobenzenesulfonamide, N-bromoacetamide, ditelluratocuprate(III), 2,2- bipyridium chlorochromate, benzo-dipteridine etc. Although hydroxy acids have been utilized for a number of catalyzed reactions, nobody has examined the role of catalysts in NBN oxidation of hydroxy acids. Malic acid is a key intermediate in the major biochemical energy-producing cycle in cells, known as the Kreb's cycle, it takes place in the cells mitochondria in most living organisms. The body synthesizes malic acid during the process of converting carbohydrates to energy. Preliminary evidence suggests that individuals with the disease fibromyalgia (a disorder that involves fatigue and pain in the muscles) might have difficulty in creating or utilizing malic acid . Such a deficiency could interfere with normal muscle function. The presence of micelles can have marked effects on thermodynamic favorability and reaction kinetics as well as on many physical properties ${ }^{1}$. Organic reactions involving ionic, polar and neutral reactants in micellar solution are generally believed to occur in the stern layer of a micelle of an ionic surfactant. The catalysis and inhibition by ionic micelles is due to ionic micellar incorporation of both the reactants. Due to these facts a significant amount of systematic kinetic results have been reported on the effect of micelles on various organic reactions during past few decades.

A.K. Singh[1] studied the kinetics and mechanism of oxidation of some lactose by Nbromophthalimide. 
Chand Waqar [2] investigated the mechanism of $\mathrm{Ru}(\mathrm{III})$-catalysed oxidation of glycollic and mandelic acids with $\mathrm{N}$-bromosuccinimide in acidic media.

Pradeep K. Sharma[3] reported the oxidation of some $\alpha$-hydroxy acids by tetraethylammonium chlorochromate.

Ajaya Kumar Singh[4] followed the kinetic and mechanistic study on the oxidation of hydroxy acids by N-bromophthalimide in the presence of a micellar system.

E.V. Sundaram[5] explained the oxidation of $\alpha$-hydroxy acids with Quinolinium Dichromate .

Asim K Das[6] studied the micellar effect on the reaction of Chromium(VI) oxidation of some representative alpha-hydroxy acids in the presence and absence of 2,2'-bipyridyl in aqueous acid media.

A perusal of literature shows that the reactivity of N-bromonicotinamide (NBN) could be compared with other $\mathrm{N}$-bromoimide such as $\mathrm{N}$-bromosuccinimide (NBS) and N-bromosaccharin (NBSa). Since NBN is more stable than the latter, it is extremely stable in solid state when kept out of light and moisture. Its standard solution has excellent keeping qualities. There are several reports available in the literature on the oxidation of alpha-hydroxy acids by oxidants such as Nbromosuccinimide, N-bromoacetamide, potassium bromate, N-bromobenzenesuphonamide, and iodate[7]. However, the details of oxidation of malic acid by N-bromonicotinamide are yet unknown. This prompted the micellar effect on the kinetics of the oxidation of the malic acid by NBN in the acidic medium.

\section{EXPERIMENTAL}

\subsection{Materials}

N-Bromonicotinamide (NBN) was prepared by the reported method[8]. The melting point of the sample was found to be $483 \mathrm{~K}$. Solutions of NBN were prepared in $80 \%$ acetic acid and stored in a black-coated flask to prevent photochemical deterioration. The prepared solution was then standardized iodometrically against standard sodium thiosulphate using starch as indicator. Standard solutions of SDS (GR) and malic acid (Merck) were prepared using double distilled water. The standard solution of mercuric acetate (Merck) was acidified with $20 \%$ acetic acid. $\mathrm{HClO}_{4}$ (A.R. grade) diluted with double distilled water was standardized via acid-base titration. All other standard solutions of $\mathrm{NaClO}_{4}, \mathrm{KCl}, \mathrm{KBr}$ and nicotinamide were prepared using double distilled water. Double distilled water was distilled over $\mathrm{KMnO}_{4}$ in an all glass (Pyrex) distillation set up. Distilled acetic acid was used throughout the experiment.

\subsection{Kinetic Measurements}

The solution of malic acid and oxidant were kept in black coated bottles separately. These solutions were kept in the thermostat to attain the thermostatic temperature. The appropriate quantity of oxidant was added to the substrate containing surfactant and other reagents and the reaction bottle was shaken well. The reaction was followed potentiometrically by setting up a cell made up of the reaction mixture into which the platinum electrode and reference electrode(SCE) were dipped. The e.m.f of the cell was measured periodically using a Equip-Tronics (EQ-DGD) potentiometer. The reactions were studied at constant temperature $35^{\circ} \mathrm{C}$. Different studies such as variation of malic acid, oxidant $(\mathrm{NBN})$, perchloric acid, sodium perchlorate, nicotinamide, surfactant and temperature were carried out. The reaction was carried out under pseudo-first order condition ([malic acid] $>>[\mathrm{NBN}]$ ). The pseudo-first order rate constants computed from the linear $\left(r^{2}>0.9990\right)$ plots of $\log \left(E_{t}-E_{\infty}\right)$ against time. Duplicate kinetic runs showed that the rate constants were reproducible within $\pm 3 \%$. The course of the reaction was studied for more than two half-lives. 


\subsection{STOICHIOMETRY}

The reaction mixture containing a known excess of $[\mathrm{NBN}]>>[\mathrm{MA}]$ was kept in presence of $\mathrm{HClO}_{4}, \mathrm{Hg}(\mathrm{OAc})_{2}$ and surfactant at $35^{\circ} \mathrm{C}$ for $72 \mathrm{~h}$. After completion of the reaction, the unconsumed NBN was calculated iodometrically. It was found that nearly 1 mole of NBN was consumed for each mole of malic acid.<smiles>[NH3+][NH3+]</smiles>

Malic acid<smiles>CCC(=O)OC(=O)O</smiles>

2-Aldoethanoic acid

\subsection{PRODUCT ANALYSIS}

The presence of 2-aldoethanoic acid as the main oxidation products was detected by the spot test [9] and the 2,4-dinitrophenylhydrazine method [10].

\subsection{CMC DETERMINATION}

Surfactants spontaneously aggregate above a certain concentration called critical micelle concentration $(\mathrm{CMC})$ to form micelle, whose determination has considerable practical importance, normally to understand the self-organizing behavior of surfactants in exact ways. Micelles act as microreactors, which both speed or inhibit the rate of uni- and bimolecular reactions. Micelle aggregates affect chemical reactivity primarily by binding or excluding reactants and only secondarily by changing the free energy of activation. The critical micelle concentration values of the surfactant (SDS) was determined conductometrically (Digital conductivitymeter, model 611E, Electronic India Company) in the presence and absence of reactants at $40^{\circ} \mathrm{C}$. The $\mathrm{CMC}$ value was determined from plot of the specific conductivity versus surfactant concentration. The breakpoints of nearly straight-line portions in the plot are taken as an indication of micelle formation, and this correspond to the CMC of surfactant. The CMC values of SDS in different experimental conditions at $40^{\circ} \mathrm{C}$ are summarized in Table 1 . The CMC value is lower than that given in the literature for aqueous solutions of SDS without added electrolyte, which was found to be approximately about $3.18 \times 10^{-3} \mathrm{~mol} \mathrm{dm}^{-3}$ in reaction mixture for malic acid.

Table 1.- Critical micelle concentration (CMC values of SDS in different experimental conditions)

\begin{tabular}{|l|c|}
\hline Solutions & $\begin{array}{l}10^{3} \mathrm{CMC} \\
\mathrm{mol} \mathrm{dm}^{-3} \mathbf{S D S}\end{array}$ \\
\hline Water & 8.3 \\
\hline Water+NBN & 7.6 \\
\hline Water+malic acid & 4.9 \\
\hline Water+malic acid $+\mathrm{NBN}+\mathrm{Hg}(\mathrm{OAc})_{2}+\mathrm{HClO}_{4}+20 \% \mathrm{v} / \mathrm{v} \mathrm{AcOH}$ & 3.5 \\
\hline
\end{tabular}

[Malic acid $]=0.03 \mathrm{~mol} \mathrm{dm}^{-3} \quad\left[\mathrm{HClO}_{4}\right]=0.01 \mathrm{~mol} \mathrm{dm}^{-3}$,

$\left[\mathrm{NaClO}_{4}\right]=0.1 \mathrm{~mol} \mathrm{dm}^{-3}, \quad \mathrm{Hg}\left(\mathrm{CH}_{3} \mathrm{COO}\right)_{2}=0.001 \mathrm{~mol} \mathrm{dm}^{-3}, \quad$ AcOH: $\mathrm{H}_{2} \mathrm{O}(1: 4) \quad$ Temp. $=308 \mathrm{~K}$

\section{RESULTS}

The kinetic results for the oxidation of malic acid by N-Bromonicotinamide (NBN) in the presence of surfactant (SDS) can be summarized as follows. The kinetic studies were carried out under pseudo-first order conditions with [malic acid] $>>$ [NBN].

All the investigations were carried out under the conditions where $\left[\mathrm{Hg}(\mathrm{OAc})_{2}\right]$ to eliminate bromide ions as $\left[\mathrm{HgBr}_{4}\right]^{2-}$, which could have been produced and might set another parallel oxidation[11]. The kinetics of the oxidation of malic acid by NBN in presence of surfactant (SDS), $\mathrm{HClO}_{4}$ and $\mathrm{Hg}(\mathrm{OAc})_{2}$ was investigated at several initial concentrations of the reactant. The reaction was of first order linearity of a plot of $\log [\mathrm{NBN}]$ versus time for malic acid. The rate constants at different initial $[\mathrm{NBN}]$ are reported. 
Table 2 summarizes the pseudo first order rate constant's dependence on the NBN concentration. It was observed that, with the increase in initial NBN concentration, the value of rate constant decreased. At a constant value of $\mathrm{NBN}$, surfactant(SDS), $\mathrm{Hg}(\mathrm{OAc})_{2}, \mathrm{HClO}_{4}$ the rate constant was determined at different initial concentrations of malic acid ranging from $5 \times 10^{-3}$ to $50 \times 10^{-3} \mathrm{~mol}$ $\mathrm{dm}^{-3}$. Table 3 summarizes the pseudo first order rate constant's dependence on malic acid concentration. The rate constant, increased with increasing [malic acid]. The plot of log k versus log [malic acid] was linear with a slope of less than unity showing fractional order dependence on [malic acid]. Furthermore, a plot of log k versus malic acid was linear with an intercept on y axis, confirming the fractional order dependence on substrate. The rate constant $\mathrm{k}$ decreased with increase in $\left[\mathrm{HClO}_{4}\right]$ from $5 \times 10^{-3}$ to $50 \times 10^{-3} \mathrm{~mol} \mathrm{dm}^{-3}$ (Table 2). This may be due to protonation of the substrate. The plot of $\log \mathrm{k}$ versus $\log \left[\mathrm{HClO}_{4}\right]$ is linear with negative slope. The slope being less than unity indicates inverse fractional order dependence on $\left[\mathrm{HClO}_{4}\right]$. Addition of mercuric acetate to the reaction mixture showed an insignificant effect on the rate of reaction, suggesting that mercuric acetate act as a bromide ion scavenger only in the form of $\left[\mathrm{HgBr}_{4}\right]^{2-}$. Successive addition of nicotinamide (as one of the oxidation products of NBN) to the reaction mixture showed a decreasing effect on the rate of oxidation of malic acid. Addition of $\mathrm{NaClO}_{4}$ (to study the effect of ionic strength) in the reaction mixture showed an insignificant effect on the rate of oxidation. In order to find the effect of dielectric constant (polarity) of the medium on the rate, the oxidation of malic acid by NBN was studied in aqueous acetic acid mixtures of various compositions (Table 2). The data clearly reveal that the rate of reaction increases with a decrease in the percentage of acetic acid, i.e., increasing dielectric constant or polarity of the medium leads to the inference that there is a charge development in the transition state involving a more polar activated complex than the reactants[12].

Table 2- Effect of variation of [NBN] on reaction rate

$[$ Malic acid $]=0.03 \mathrm{~mol} \mathrm{dm}^{-3} \quad\left[\mathrm{HClO}_{4}\right]=0.01 \mathrm{~mol} \mathrm{dm}^{-3}$, $\left[\mathrm{NaClO}_{4}\right]=0.1 \mathrm{~mol} \mathrm{dm}{ }^{-3}, \quad \mathrm{Hg}\left(\mathrm{CH}_{3} \mathrm{COO}\right)_{2}=0.001 \mathrm{~mol} \mathrm{dm}^{-3}$,

\begin{tabular}{|c|c|c|}
\hline \multirow{2}{*}{$\mathrm{AcOH}: \mathrm{H}_{2} \mathrm{O}(1: 4)$} & \multirow{2}{*}{ Temp. $=308 \mathrm{~K}$} & \multirow{2}{*}[\mathrm{SDS}]{$=0.004 \mathrm{~mol} \mathrm{dm}^{-3}$} \\
\hline & & \\
\hline & $\begin{array}{c}{[\mathrm{NBN}]} \\
10^{4} \mathrm{moldm}^{-3}\end{array}$ & $10^{5} \mathrm{k}_{\mathrm{obs}} \sec ^{-1}$ \\
\hline & 1.0 & 41.96 \\
\hline & 1.5 & 31.69 \\
\hline & 2.0 & 26.97 \\
\hline & 2.5 & 24.01 \\
\hline & 3.0 & 21.97 \\
\hline & 4.0 & 19.54 \\
\hline & 5.0 & 17.95 \\
\hline
\end{tabular}

Table 3- Effect of variation of [Malic acid], $\left[\mathrm{HClO}_{4}\right]$ and the dielectric constant on reaction rate $[\mathrm{NBN}]=0.00015 \mathrm{~mol} \mathrm{dm}^{-3} \quad\left[\mathrm{NaClO}_{4}\right]=0.1 \mathrm{~mol} \mathrm{dm}^{-3}$, $\mathrm{Hg}\left(\mathrm{CH}_{3} \mathrm{COO}\right)_{2}=0.001 \mathrm{~mol} \mathrm{dm}^{-3}$, Temp. $=308 \mathrm{~K}[\mathrm{SDS}]=0.004 \mathrm{~mol} \mathrm{dm}^{-3}$

\begin{tabular}{|c|c|c|c|}
\hline $10^{3}[\mathrm{MA}]$ & $\mathbf{1 0}^{3}\left[\mathrm{HClO}_{4}\right]$ & $\begin{array}{c}\mathbf{C H}_{3} \mathbf{C O O H} \\
\%(\mathbf{v} / \mathbf{v})\end{array}$ & $\begin{array}{c}\mathbf{1 0}^{5} \mathbf{k}_{\text {(obs) }} \\
\mathbf{s e c}^{-1}\end{array}$ \\
\hline 5 & 10 & 20 & 11.52 \\
\hline 10 & 10 & 20 & 17.95 \\
\hline 20 & 10 & 20 & 27.58 \\
\hline 25 & 10 & 20 & 31.74 \\
\hline 30 & 10 & 20 & 36.19 \\
\hline 40 & 10 & 20 & 42.95 \\
\hline 50 & 10 & 20 & 48.97 \\
\hline 30 & 5 & 20 & 50.59 \\
\hline 30 & 10 & 20 & 31.92 \\
\hline 30 & 20 & 20 & 20.62 \\
\hline
\end{tabular}




\begin{tabular}{|l|l|l|l|}
\hline $\mathbf{3 0}$ & $\mathbf{2 5}$ & $\mathbf{2 0}$ & $\mathbf{1 7 . 6 5}$ \\
\hline $\mathbf{3 0}$ & $\mathbf{3 0}$ & $\mathbf{2 0}$ & $\mathbf{1 5 . 5 9}$ \\
\hline 30 & $\mathbf{4 0}$ & $\mathbf{2 0}$ & $\mathbf{1 2 . 8 6}$ \\
\hline 30 & $\mathbf{5 0}$ & $\mathbf{2 0}$ & $\mathbf{1 1 . 1 2}$ \\
\hline 30 & 10 & $\mathbf{2 0}$ & $\mathbf{3 0 . 9 7}$ \\
\hline 30 & 10 & $\mathbf{2 5}$ & $\mathbf{2 8 . 1 1}$ \\
\hline 30 & 10 & $\mathbf{3 0}$ & $\mathbf{2 4 . 9 2}$ \\
\hline 30 & $\mathbf{1 0}$ & $\mathbf{4 0}$ & $\mathbf{1 8 . 5 7}$ \\
\hline 30 & 10 & $\mathbf{5 0}$ & $\mathbf{1 2 . 5 1}$ \\
\hline
\end{tabular}

The effect of added salts on the rate of reaction was also explored because salts as additives, in micellar systems, acquire a special ability to induce structural changes which may, in turn, modify the substrate-surfactant interaction. In the present case, $\mathrm{KCl}$ has no effect whereas with the increasing concentration of $\mathrm{KBr}$, rate of reaction increased.

\section{Test for Free Radicals}

To test for the presence of free radicals in the reaction, the reaction mixture containing acrylamide was kept for $24 \mathrm{~h}$ in an inert atmosphere. When the reaction mixture was diluted with methanol, the formation of a precipitate was not seen. This suggests that there is no possibility of formation of free radicals in the reaction.

\section{Influence of SDS on $\mathbf{k}_{\mathbf{o b s}}$}

A continuous decrease in the rate constant was observed with the increase in [SDS] at constant [MA] and [NBN] (Table 4). The inhibition effect is due to the fact that N-bromonicotinamide has $\mathrm{N}$ -Br bond which it binds to SDS micelles in Stern layer, while ionized malic acid, bearing negative charge is repelled by the head group of negatively charged SDS micelles.

Table 4-Effect of [SDS] on reaction rate [Malic acid $]=0.03 \mathrm{~mol} \mathrm{dm}^{-3}\left[\mathrm{HClO}_{4}\right]=0.01 \mathrm{~mol} \mathrm{dm}^{-3}$, $[\mathrm{NBN}]=0.0015 \mathrm{~mol} \mathrm{dm}^{-3} \quad\left[\mathrm{NaClO}_{4}\right]=0.1 \mathrm{~mol} \mathrm{dm}^{-3}$, AcOH: $\mathrm{H}_{2} \mathrm{O}(1: 4) \quad \mathrm{Hg}\left(\mathrm{CH}_{3} \mathrm{COO}\right)_{2}=0.005 \mathrm{~mol} \mathrm{dm}^{-3}$ Temp. $=308 \mathrm{~K}$

\begin{tabular}{|c|c|}
\hline $10^{3} \mathbf{S D S}$ & $\mathbf{1 0}^{\mathbf{5}} \mathbf{k}_{\text {(obs) }} \mathbf{S e c}^{-1}$ \\
\hline 0 & 28.75 \\
\hline 2 & 25.42 \\
\hline 2.5 & 23.11 \\
\hline 4 & 21.08 \\
\hline 5 & 19.33 \\
\hline 6 & 17.65 \\
\hline 8 & 16.78 \\
\hline 10 & 15.39 \\
\hline 20 & - \\
\hline 30 & - \\
\hline 40 & - \\
\hline 50 & - \\
\hline 60 & - \\
\hline 70 & - \\
\hline 80 & - \\
\hline 100 & - \\
\hline 110 & - \\
\hline 120 & - \\
\hline 130 & - \\
\hline
\end{tabular}




\section{Effect of temperature}

Increase in temperature increases the rate of oxidation and plot of $\log \mathrm{k}_{\mathrm{obs}}$ Vs reciprocal of temperature is linear. The oxidation of malic acid by NBN was studied at different temperatures in the presence and absence of SDS (308 to 323K) (Table 5) and the activation parameters were evaluated (Table 6). Activation parameters are believed to provide useful information regarding the environment in which chemical reactions take place.

Table 5. Effect of Temperature on reaction rate

[Malic acid $]=0.03 \mathrm{~mol} \mathrm{dm}^{-3}\left[\mathrm{HClO}_{4}\right]=0.01 \mathrm{~mol} \mathrm{dm}^{-3}$, $[\mathrm{NBN}]=0.0015 \mathrm{~mol} \mathrm{dm}^{-3} \quad\left[\mathrm{NaClO}_{4}\right]=0.1 \mathrm{~mol} \mathrm{dm}^{-3}$, AcOH: $\mathrm{H}_{2} \mathrm{O}(1: 4) \quad \mathrm{Hg}\left(\mathrm{CH}_{3} \mathrm{COO}\right)_{2}=0.005 \mathrm{~mol} \mathrm{dm}^{-3}$

\begin{tabular}{|c|c|}
\hline $\begin{array}{c}\text { Temperature } \\
\mathbf{K}\end{array}$ & $\mathbf{1 0}^{\mathbf{5}} \mathbf{K}_{\mathbf{o b s}} \mathbf{s e c}^{\mathbf{- 1}}$ \\
\hline 308 & 30.93 \\
\hline 313 & 35.50 \\
\hline 318 & 40.31 \\
\hline 323 & 45.87 \\
\hline
\end{tabular}

Effect of Temperature on reaction rate in the presence of SDS

$$
[\mathrm{SDS}]=0.004 \mathrm{~mol} \mathrm{dm}^{-3}
$$

\begin{tabular}{|c|c|c|c|c|}
\hline Substrate & $\mathbf{E}_{\mathrm{a}} \mathrm{kJmol}^{-1}$ & $\Delta \mathbf{H}^{\#} \mathbf{k J m o l}^{-1}$ & $\Delta \mathbf{S}^{\#} \mathbf{J} \mathbf{K}^{-1} \mathbf{m o l}^{-1}$ & $\Delta \mathrm{G}^{\#} \mathrm{KJmol}^{-1}$ \\
\hline Malic acid & $\cdot 11.90$ & 9.34 & -183.7 & 65.93 \\
\hline Malic acid+SDS & 12.86 & 10.30 & -180.6 & 65.93 \\
\hline
\end{tabular}

Table 6- Activation Parameters

\begin{tabular}{|c|c|}
\hline $\begin{array}{c}\text { Temperature } \\
\mathbf{K}\end{array}$ & $\mathbf{1 0}^{\mathbf{5}} \mathbf{k}_{\mathbf{o b s}} \mathbf{S e c}^{-\mathbf{1}}$ \\
\hline 308 & 29.98 \\
\hline 313 & 33.66 \\
\hline 318 & 37.39 \\
\hline 323 & 41.61 \\
\hline
\end{tabular}

\section{Mechanism}

It has been reported [13] earlier that NBN is a stable oxidizing and brominating agent because of the large polarity of the $\mathrm{N}-\mathrm{Br}$ bond. NBN, like other similar $\mathrm{N}$-haloimides, may exist in various forms in an acidic medium, that is, free $\mathrm{NBN}$, protonated $\mathrm{NBN}, \mathrm{Br}^{+}, \mathrm{HOBr},\left(\mathrm{H}_{2} \mathrm{OBr}\right)^{+}$according to the following equilibria [13].

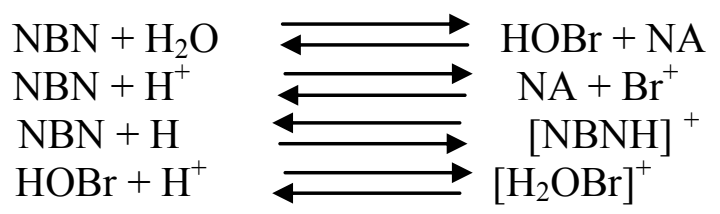


Addition of nicotinamide to the reaction mixture decreases the rate of oxidation in acidic media suggesting that the pre-equilibrium step involves a process in which nicotinamide is one of the products. When NBN or $(\mathrm{NBNH})^{+}$is assumed as the reactive species, the derived rate laws fail to explain the negative effect of nicotinamide, hence neither of these species can be considered as reactive species. When $\left(\mathrm{H}_{2} \mathrm{OBr}\right)^{+}$is taken as the reactive species, the rate law obtained shows first order kinetics with respect to hydrogen ion concentrations contrary to the observed negative fractional order in $\mathrm{HClO}_{4}$; although it fully explains the negative effect of nicotinamide. Therefore, the possibility of cationic bromine $\left(\mathrm{Br}^{+}\right)$as a reactive species is also ruled out. Thus, the only choice left is $\mathrm{HOBr}$, which, when considered as the reactive species of NBN, leads to a rate law capable of explaining all the kinetics observations and other effects. Hence, in the light of kinetic observations, $\mathrm{HOBr}$ can safely be assumed to be the main reactive species of NBN for the present reaction. On the basis of the above experimental findings and taking $\mathrm{HOBr}$ to be the most reactive species of NBN, the following scheme can be proposed for the kinetics of oxidation of tartaric acid by NBN in acidic medium.

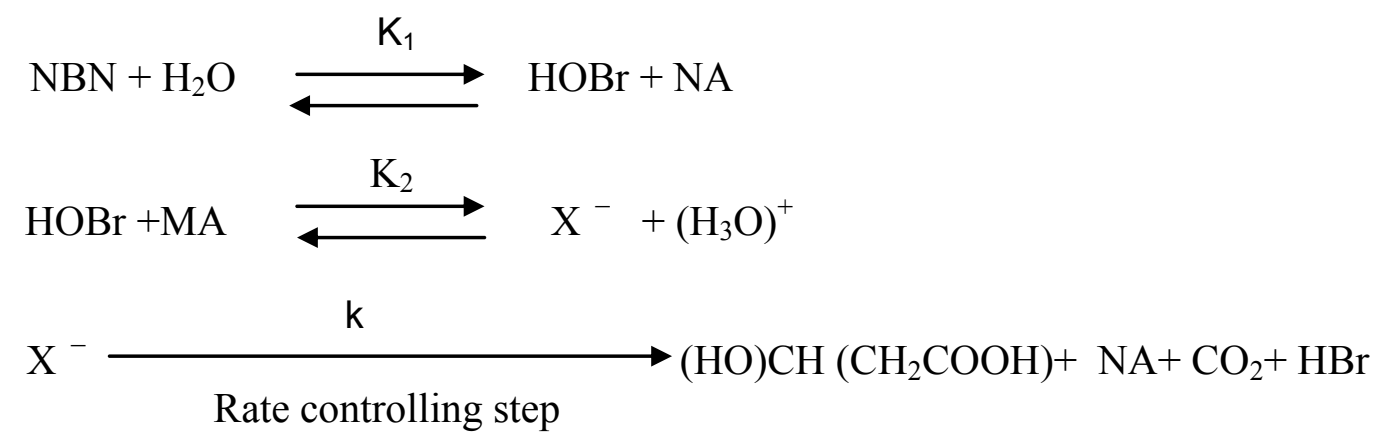

According to above scheme, the rate of disappearance of NBN is given as

$-\frac{d[N B N]}{d T}=\frac{k K 1 K 2[M A][N B N] T O T A L}{[N A][H+]+K 1 K 2[M A]}$

where

$[\mathrm{NBN}]_{\text {TOTAL }}=[\mathrm{NBN}][\mathrm{NA}]\left[\mathrm{X}^{-}\right]$

The above rate law is in good agreement with the experimental results.

\section{Influence of SDS on $\mathbf{k}_{\mathbf{o b s}}$}

The inhibition effect is due to the fact that $\mathrm{N}$-bromonicotinamide has $\mathrm{N}-\mathrm{Br}$ bond which it binds to SDS micelles in Stern layer, while ionized malic acid, bearing negative charge is repelled by the head group of negatively charged SDS micelles.

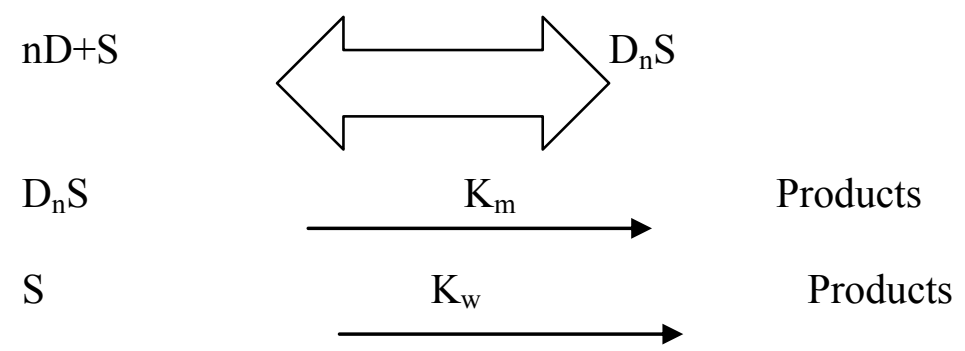

Piszkiewicz[14] model assumes that ' $n$ ' number of surfactant molecules (D) and substrate (S) aggregate to yield the catalysis aggregate $\mathrm{D}_{\mathrm{n}} \mathrm{S}$ which then reacts to yield the product $(\mathrm{P})$. This is represented by the above scheme where $\mathrm{K}_{\mathrm{D}}$ is the dissociation constant of micelle back to its free components and $\mathrm{K}_{\mathrm{m}}$ is the rate of reaction within the micelle. As per the above scheme the observed rate constant $\left(\mathrm{k}_{\mathrm{obs}}\right)$ is expressed as a function of surfactant concentration $\mathrm{D}$, by the equation: 


$$
\begin{aligned}
& \mathrm{k}(\mathrm{obs})=\frac{K_{m}[D] n+k w K_{D}}{K_{D}+[D] n} \\
& \log \frac{k(o b s)-k w}{K_{m}-k(o b s)}=n \log [\mathrm{D}]-\log \mathrm{K}_{\mathrm{D}}
\end{aligned}
$$

\section{CONCLUSIONS}

In the light of kinetic observations for the micellar effect on the kinetics of oxidation of malic acid by N-bromonicotinamide in the presence of perchloric acid, the following conclusions can be easily drawn: the reactive species of oxidant NBN is HOBr not NBN itself, the reaction rates are enhanced by increase in [malic acid] and temperature. Added nicotinamide retards the rate. 2Aldoethanoic acid is the product of oxidation. Activation parameters were evaluated for both catalyzed and unanalyzed reactions. The critical micelle concentration value is much lower than that given in the literature for aqueous solutions of SDS without added electrolyte. The rate of oxidation slightly decreases with increasing concentration of SDS. The micellar effect can be correlated with the nature of the reducing substrates and the reactions conditions. These micellar effects are quite important to understand and to substantiate the proposed mechanistic pathways. This may widen the applicability of NBN as oxidant in organic synthesis.

\section{ACKNOWLEDGEMENTS}

The author gratefully acknowledges her husband Mr. A. Ramesh for the moral support.

\section{References}

[1]. Madhu Saxena, Ranjana Gupta, Amar Singh, Bharat Singh, Singh A. K., Journal of Molecular Catalysis. 65(3) (1991) 317.

[2]. Chand Waqar, Bharat Singh, Sharma J.P., Journal of Molecular Catalysis. 60(1) (1990) 49.

[3]. Preeti Swami D., Yajurvedi P. Mishra, Pradeep K. Sharma, International Journal of Chemical Kinetics. 42(1) (2010) 50.

[4]. Patil Sangeeta, Katre Y. R., Ajaya Kumar Singh, Journal of surfactants and detergents. 10(3) (2007) 175.

[5]. Kailasa Aruna, Prerepa Manikyamba, Embar Venkatachari Sundaram, Collection of Czechoslovak Chemical Communications. 58(7) (1978) 1624.

[6]. Ruhidas Baeyen, Mohirul Islam, Asim K. Das, Indian Journal of chemistry. 48A (2009)1055.

[7]. Sangeeta Patil, Katre Y.R., Ajaya Kumar Singh, Colloids and Surfaces. A: Physicochem. Eng. Aspects. 308 (2007) 6.

[8]. Hauser C.R., Renfrow Jr W.B., J. Am. Chem. Soc. 59(1923)121.

[9]. F. Feigl, "Spot test in organic analysis", Elsevier, New York, (1975) 425.

[10]. Mathur A., Sharma V, Banerji K.K., Indian J. Chem. 27A (1988) 123.

[11]. Ch,S. Reddy, T.V. Kumar, Indian J. Chem. 34A (1995) 871.

[12]. K.J. Laidler, “CChemical Kinetics” Tata Mc. Graw Hill New Delhi (1965) 229.

[13]. (a). Pushpalatha L., Vivekanandan K., J. Indian Chem. Soc. 86 (2009 ) 475.

(b). Pushpalatha L., Vivekanandan K., Oxid. Commun. 32(1) (2013) 85.

(c). Pushpalatha L., Vivekanandan K., Oxid. Commun. 31(3) (2008) 598.

(d). Pushpalatha L., Oxid. Commun., 35(4) (2013) 901. 
(e). Pushpalatha L., Oxid. Commun. 35(4) (2013) 952.

(f).Pushpalatha L., Oxid. Commun. 35(4) (2013) 938.

(g). Pushpalatha L., Vivekanandan K., Oxid. Commun. 35(3) (2013) 583.

(h). Pushpalatha L., Vivekanandan K., Oxid. Commun. 35(4) (2013) 914.

(i) Pushpalatha L., Vivekanandan K., Abubacker M. N.,

J. Indian Chem. Soc. 90 (2013)1027.

(j). Pushpalatha L., Oxid. Commun. 35(4) (2013) 926.

[14]. Piszkiewicz D.J., J. Am. Chem. Soc. 99 (1977) 7695. 